\title{
Design Thinking in Engineering Course Design
}

\section{Dr. Nicholas D. Fila, Iowa State University}

Nicholas D. Fila is a postdoctoral research associate in Electrical and Computer Engineering and Industrial Design at Iowa State University. He earned a B.S. in Electrical Engineering and a M.S. in Electrical and Computer Engineering from the University of Illinois at Urbana-Champaign and a Ph.D. in Engineering Education from Purdue University. His current research interests include innovation, empathy, design thinking, instructional design heuristics.

\section{Dr. Seda McKIlligan, Iowa State University}

Dr. McKilligan's research focuses on approaches in the design innovation process, ideation flexibility, investigations of problem-solution spaces, and concept generation and development practices of novices through practitioners. She produces theory, design principles and systems to support design, engineering and educational innovation processes, through studying experiences of individuals and teams that lead to innovative thinking and through integrating that knowledge into organizational change.

\section{Kelly Guerin, Iowa State University}

Kelly Guerin is an Undergraduate Research Assistant at Iowa State University. She is a junior pursuing a Bachelor of Industrial Design. 


\title{
Design Thinking in Engineering Course Design
}

\begin{abstract}
Design thinking is a robust framework for creatively and effectively identifying and solving important human problems. While design thinking is commonly associated with fields like industrial design, it can be applied to many problem types. For example, several recent examples demonstrate the applicability of design thinking to the design and development of educational materials, courses, and systems. These results suggest that design thinking could be used as a framework to (re)design and develop effective engineering courses. The goal of this project is to understand how nine educators from different backgrounds did or did not use design thinking to redesign a sophomore-level electrical and computer engineering course. The primary source of data was 21 transcribed audio recordings of design meetings and is supplemented with interviews, reflections, and course artifacts. Thematic analysis revealed 10 themes that represent connections and disconnections between the process used and a common five-stage design thinking process (empathize, define, ideate, prototype, and test). These themes demonstrate some of the opportunities and challenges related to design thinking within an engineering course design setting. In particular, they suggest that engineering course design is a relevant context for design thinking, but one to which design thinking methods do not always naturally translated. Future work should focus on better understanding unique applications of design thinking within engineering course design and methods that might to support more designerly behaviors among engineering educators.
\end{abstract}

\section{Introduction}

Design thinking is an effective way to meet human needs creatively and appropriately ${ }^{1}$. While design thinking is often associated with traditional design fields such as industrial design and architecture, it has been extended to a variety of non-traditional settings. One of these settings is the design of courses and curricula. For example, IDEO, a leading design consultancy, has developed a toolkit that explores the application of design thinking for educators and presents several successful examples of course and curriculum reimagining using design thinking ${ }^{2}$.

The translation of design thinking to education contexts is not surprising. Scholars have noted similarities between design thinking and the models and practices used by expert instructional designers $^{3}$. For example, learner and context analysis are often important features of expert models and practices ${ }^{3-6}$ and connect to the empathic and user-oriented aspects of design ${ }^{7}$. However, scholars also recognize that differences between settings, even within instructional design, may favor different practices ${ }^{4}$. Literature on the role design thinking can play in education settings is emerging, but more work is needed to understand how design thinking can be applied to the design of engineering courses and curricula, and how the unique features of these settings may affect such applications.

This work reports on a part of a larger study where the core technical ECE curriculum at a large university in the midwestern United States is reshaped through novel and proven pedagogical 
approaches to (a) promote design thinking, systems thinking, professional skills such as leadership, and inclusion; (b) contextualize course concepts; and (c) stimulate creative, sociotechnical-minded development of ECE technologies for future smart systems, including security and privacy. Using iterative design thinking process and reflection, the instructional teams explore professional formation pedagogy (PFP) strategies and integrate them into courses ${ }^{8,9}$. As part of the larger study, this paper investigates the use of design thinking in the processes of a cross-functional team redesigning a second-year course for electrical, computer, and software engineering students. This team provides a suitable setting for the current study for two reasons. First, the team was composed of nine individuals with diverse experiences related to design thinking. Thus, we were able to explore approaches by novices and experts as they applied design thinking in a new setting. Second, the design effort focused on an established course, which (a) allowed us to better understand the effect of past iterations and extant structures and (b) provided a setting closely relatable to many engineering educators who may wish to use design thinking in educational settings.

Thus, in this study, we attempt to address the following research question:

How do engineering educators apply design thinking processes to the redesign of an established, second-year electrical, computer, and software engineering course?

\section{Literature Review}

\section{What is design thinking?}

Design thinking was first used by Herbert Simon in his book called The Sciences of the Artificial ${ }^{10}$ which became topic of interest to many design researchers ${ }^{11}$. The Design Thinking Research Symposium was one of the initial explorations of design thinking as a new methodology for creative problem solving ${ }^{12}$. Today, its application has been extended to address wider problems - ways for companies and other groups to identify new strategic directions, innovate new service possibilities, or implement procedural change. In the past, what we now identify as design thinking was often driven by tacit knowledge, intuition, and personal preference of expert designers. The potential now is to enhance this approach through crossdisciplinary, evidence-based research.

Due to the widespread use of design thinking, and the preponderance of practical and academic literature, many conceptualizations exist. However, a recent study by Carlgren, Rauth, and Elmquist ${ }^{7}$, sought to bridge these gaps by exploring the literature and conducting interviews with members of six leading organizations. The result was a framework, aligned with both the academic literature and authentic practice, that presents design thinking activity across three levels of abstraction: (1) mindsets that underlie, orient, and motivate design thinking; (2) overarching practices, imbued with the aforementioned mindsets, that guide design thinking as a process; and (3) specific techniques that are used by design thinkers and support design thinking among non-experts. 
Mindsets lie at the center of design thinking. These are individual beliefs and tendencies that orient action. For example, the empathetic mindset, which values user engagement throughout the design process and emphasizes development of empathetic, contextualized understanding of users, is a key design thinking mindset ${ }^{7,13-15}$. While many sets of mindsets have been identified in the academic and practical literature (e.g., ${ }^{7,13-15}$ ), Schweitzer $^{15}$ and colleagues have defined a nearly comprehensive set of 11 mindsets through a literature review and interview study. These mindsets include orientations toward:

1. Empathetic towards people's needs and context - engaging users in the design process, developing empathy for unique users, and guiding design work based on authentic user needs.

2. Collaboratively geared and embracing diversity - working effectively with people with a variety of expertise and perspectives, especially with respect to promoting positive team dynamics, ensuring participation, communicating/listening, and embracing all team members.

3. Inquisitive and open to new perspectives and learning - learning, discovery, and exploration. It is marked by curiosity, an open mind, and engagement with new ideas and perspectives.

4. Mindful of process and thinking modes - meta-level awareness of how the team or the participant is or is not utilizing design thinking mindsets and processes (or where team is strong and or lacking) and using that awareness to guide team and individual behavior.

5. Experiential intelligence - communicating and trying out ideas, especially through increasing the tangibility and visualization of ideas, and building and iterating upon ideas.

6. Taking action deliberately and overtly - acting rather than discussing and a preference to move into the real world.

7. Consciously creative - generating a great variety and volume of ideas and nurturing creative behavior among oneself and others.

8. Accepting uncertainty and open to risk - engaging with uncertainty in the design process. This involves holistic thinking, engaging with conflicting criteria and constraints, and acting with limited information.

9. Modeling behavior - modelling and promoting DT behavior and mindsets within the team.

10. Desire and determination to make a difference - positivity, hope, and creating change. This behavior is often marked by resilience, determination, and optimism.

11. Critically questioning - focusing on the design problem, deconstructing and reframing design problems, questioning one's own and the team's biases.

Mindsets are essential to design thinking, but design thinking is more frequently modeled as an interconnected set of practices. For example, a popular process model includes five stages: Empathize, Define, Ideate, Prototype, and Test ${ }^{1}$. The empathize phase brings the human element into the picture and facilitates a deeper understanding of current experiences and unmet needs of stakeholders. This attention to the present as it is experienced by stakeholders helps to broaden and perhaps even change completely the definition of the problem. The define phase translates these insights into design criteria that specify what an ideal successful solution will look like, without starting to solve the problem. The ideate phase begins with generating potential solutions and new possibilities using the criteria and the insights built. The prototype and test phases focus 
on building simple, yet effective prototypes to deliver the idea and systematically evaluating them against the design criteria. In these two phases, the goal is often to elicit effective feedback through helping people "pre-experience'21 something novel to improve the accuracy of forecasting. Design thinking work moves freely between these stages, with outcomes from each stage informing iterative work in other stages.

While many such process models exist ${ }^{16}$, they generally demonstrate stages and activities comparable to Brown's model ${ }^{1}$ because these processes can be considered the manifestation of design thinking mindsets in practice. For example, the define stage in Brown's ${ }^{1}$ model focuses on developing design criteria based on authentic user needs. The inquisitive and critical questioning mindsets (numbers 3 and 11 in the list above from Schweitzer and colleagues ${ }^{15}$ ) are particularly important to this stage because of the necessity of learning from users, discovering their needs, addressing personal biases that may affect interpretation of the design problem, and continually reframing the design problem based on new ideas and perspectives from users and the design team. As such, many design process models demonstrate define or similar stages. Conversely, the techniques level represents specific activities performed by design experts, or designed to support the work of novices, the are imbued with the spirit of the design process stages.

\section{How is design thinking applied outside traditional design disciplines?}

Design thinking rests on defining different stages of innovation - discovering and describing problems via processes to connect with users and frame challenges. This inspiration evolves into stages of ideation and prototyping; opportunities for solution can then be tested and refined, to result in final implementation. Major agencies (the US Department of Health and Human Services, the Transportation and Security Administration, Food and Drug Administration) have instituted principles of design thinking to reduce risk, handle change, use resources more effectively, bridge communication gaps between parties, and manage competing demands ${ }^{17}$. For example, the FDA has used design thinking processes to create productive dialogues among diverse constituents, minimizing early confrontation. At Kaiser Permanente, a major corporation in healthcare service industry, design thinking is used to facilitate change processes within the organization. Frontline staff that have participated in projects often use the techniques learned in direct contact with patients in order to improve their work practices ${ }^{7}$. Children's Health Systems of Texas integrated design thinking into their routine problem identifying and solving process and used it to assess and build capabilities to deliver a transformational new approach to health care that focused on facilitating family wellness rather than on providing individual medical care $^{18}$.

Design thinking is being used today in organizations as diverse as charitable foundations, social innovation startups, global corporations, national governments, and elementary schools ${ }^{18}$. Although it has been increasingly adopted by small to large organizations to tackle complex problems ${ }^{1,19-21}$, suggesting it provides significant value for innovation, it hasn't been used widely in educational settings as a process for change towards innovative curriculum. Educators and researchers who saw value have reported on design thinking's integration into existing curriculum and described implications ${ }^{22-25}$. Higher education business schools in the U.S., Europe, and Asia have incorporated design teaching into their curricula, and more recently in Australia, higher education research institutions are forming programs outside of the traditional 
discourse towards investigating new processes using design thinking ${ }^{26}$. However, how design thinking as a change process would impact the curriculum design is not thoroughly investigated.

How can design thinking be used to support course and curriculum design in engineering?

Design thinking sits at the overlap of analytical thinking and intuitive thinking ${ }^{21}$. While the engineering design process relies on deductive reasoning with rational and predictable agents, the design thinking process emphasizes inductive reasoning that embraces irrational and unpredictable agents. Although both processes share certain process steps, such as iteration, testing, research, and prototyping, their applications and characteristics of these vary dramatically. Thus, while the content of engineering courses may align more with engineering design, design thinking's framework for abstraction provides a more flexible approach in understanding the conversations in course development.

Researchers and scholars have described similarities between design thinking and extant instructional design methods ${ }^{3,27}$. In particular, these connections often exist at the practice level. For example, developing empathy for users and engaging them in the process is a core principle in design thinking and is present throughout many examples of the observed and documented practices of instructional designers in the form of understanding the target learners ${ }^{4-6}$. Similarly, both design thinking and instructional design practices promote the use of scaled-down prototypes to test design concepts with users ${ }^{4,6,28,29}$.

Others have pointed out that despite the demonstrable connections between design thinking and instructional design, there are many differences in scope and implementation ${ }^{3,27,30}$. For example, while understanding users may be important in both design thinking and instructional design, instructional design models developed from expert practices often focus on understanding the prerequisite knowledge and learning capabilities of students ${ }^{5,29}$. Design thinking promotes deeper engagement with and empathy for users, including observing and interacting with users in authentic contexts to develop a deep understanding of their challenges and needs, without limiting focus to specific areas such as learning capabilities ${ }^{1,7}$. Further, studies suggest that authentic practices often differ by context (e.g., business and academia ${ }^{4}$ and expert and novice ${ }^{5}$ ), and may be affected by situational factors such as time ${ }^{31}$. Thus, expert models and practices may also provide an incomplete picture of the connections between design thinking and instructional design Ultimately, the practices of developing courses and curricula, with respect to design thinking, are still poorly understanding in engineering education practice and require further study. This study attempts to fill some of that gap by investigating the use and applicability of design thinking processes in an engineering course redesign setting.

\section{Methods}

\section{Setting and Participants}

The setting of this study was the redesign of a second-year embedded systems course that was required for electrical, computer, and software engineering students. The redesign effort was part of a federally-funded initiative to facilitate change in the Electrical and Computer Engineering 
Department at a large university in the Midwest United States ${ }^{8}$. The course redesign effort was one several such efforts in the initiative tasked with helping to shift the departmental paradigm toward student-centered teaching and learning practices and greater integration of professional formation throughout the curriculum, in a bottom-up fashion ${ }^{9}$. As an established course in the department, the course had undergone revisions in the past, but as part of the departmental initiative, the current effort emphasized (1) employing a cross-functional, cross-disciplinary " $\mathrm{X}$ team" to infuse diverse perspectives and expertise into course redesign and (2) use design thinking as a method for change. The overarching goal of the X-team was to redesign the course to (a) identify and incorporate professional formation elements (e.g., design thinking) and (b) ensure students' and instructors' needs were being met ${ }^{9}$.

A team of nine educators (Table 1) formed the X-team to make revisions to the course over each of the next four semesters (this study focused on the first semester of this effort). The team members were recruited based on their unique experiences and expertise, and each served a unique function on the team. Michael was the current instructor and had taught the course for several years. He provided expertise on course operation, content knowledge and pedagogical content knowledge related to the course, insight on computer engineering students, and served as a co-designer (both a designer and user of the eventual redesigned course). Sydney was a past instructor and original developer of the course. She provided complementary expertise related to the course and served as the project leader for the overarching departmental initiative. Freddie added expertise in student reflection, and through his unique instructional approach, a unique perspective on the electrical engineering students who took the class. Beth served as the key design thinking expert and advocate on the team. She was supported by Leo, who also brought engineering education research and course development expertise to the team and a unique perspective as a recent electrical engineering student. Stanley, Rebecca, James, and Andy were each added to the team as specialists due to their unique expertise, as reported in Table 1. As Table 1 also shows, members of the team had various levels of experience with design thinking, which was to be gently facilitated by the more experienced members of the team.

The team formed during the summer before the first course iteration (Fall 2017) and met 2-3 times per week until the semester began. The team then continued to meet once per week as a full team and once per week with Michael, Sydney, Freddie, and Leo during the Fall 2017 semester, from which data for this study was collected.

Design thinking was intended to be an overarching method used by the team and was introduced into the team process in two ways. First, Beth, Leo, and Andy acted as design thinking advocates and mentors throughout the process. Their role was not to direct the team's process, but to provide gentle encouragement and support. This included explaining design thinking and aspects thereof when needed, encouraging design thinking behaviors and mindsets, and acting as role models during design activities. Second, Beth and Leo also introduced several specific design thinking activities into the team's process to encourage more design thinking. These included two abstraction laddering ${ }^{32}$ exercises to support problem reframing and an ideation session. 
Table 1. Course Design Participants

\begin{tabular}{|c|c|c|c|c|}
\hline Pseudonym & Position & Department & X-Team Role & $\begin{array}{l}\text { Design Thinking } \\
\text { Expertise/Experience }\end{array}$ \\
\hline Michael & $\begin{array}{l}\text { Associate } \\
\text { professor }\end{array}$ & $\begin{array}{l}\text { Electrical and } \\
\text { computer } \\
\text { engineering }\end{array}$ & Current instructor & $\begin{array}{l}\text { Over a decade of engineering } \\
\text { design experience; no prior } \\
\text { knowledge of design thinking }\end{array}$ \\
\hline Sydney & Full professor & $\begin{array}{l}\text { Electrical and } \\
\text { computer } \\
\text { engineering }\end{array}$ & $\begin{array}{l}\text { Project leader; past } \\
\text { instructor }\end{array}$ & $\begin{array}{l}\text { Over a decade of engineering } \\
\text { design experience; no prior } \\
\text { knowledge of design thinking }\end{array}$ \\
\hline Freddie & $\begin{array}{l}\text { Associate } \\
\text { professor }\end{array}$ & $\begin{array}{l}\text { Industrial design; } \\
\text { electrical and } \\
\text { computer } \\
\text { engineering }\end{array}$ & $\begin{array}{l}\text { Reflection expert; } \\
\text { expert on electrical } \\
\text { engineering students in } \\
\text { the department }\end{array}$ & $\begin{array}{l}\text { Over a decade of design } \\
\text { thinking experience }\end{array}$ \\
\hline Beth & $\begin{array}{l}\text { Associate } \\
\text { professor }\end{array}$ & Industrial design & Design thinking expert & $\begin{array}{l}\text { Over a decade of design } \\
\text { thinking experience through } \\
\text { practice, teaching, and } \\
\text { research }\end{array}$ \\
\hline Stanley & $\begin{array}{l}\text { Assistant } \\
\text { professor }\end{array}$ & $\begin{array}{l}\text { Aeronautical } \\
\text { engineering }\end{array}$ & $\begin{array}{l}\text { Professional formation } \\
\text { expert; reflection } \\
\text { expert }\end{array}$ & $\begin{array}{l}\text { Some awareness of design } \\
\text { thinking through engineering } \\
\text { education research }\end{array}$ \\
\hline Leo & $\begin{array}{l}\text { Postdoctoral } \\
\text { research } \\
\text { associate }\end{array}$ & $\begin{array}{l}\text { Industrial design; } \\
\text { electrical and } \\
\text { computer } \\
\text { engineering }\end{array}$ & $\begin{array}{l}\text { Design thinking expert; } \\
\text { engineering education } \\
\text { expert; recent electrical } \\
\text { engineering student }\end{array}$ & $\begin{array}{l}\text { Five years of design thinking } \\
\text { research; limited experience } \\
\text { practicing design thinking }\end{array}$ \\
\hline Rebecca & $\begin{array}{l}\text { Postdoctoral } \\
\text { research } \\
\text { associate }\end{array}$ & Education & $\begin{array}{l}\text { Student identity } \\
\text { development expert }\end{array}$ & $\begin{array}{l}\text { No formal experience with } \\
\text { design thinking or } \\
\text { engineering design }\end{array}$ \\
\hline Jonathan & $\begin{array}{l}\text { Teaching } \\
\text { assistant }\end{array}$ & $\begin{array}{l}\text { Electrical and } \\
\text { computer } \\
\text { engineering }\end{array}$ & $\begin{array}{l}\text { Current and } \\
\text { experienced TA in the } \\
\text { course; former student } \\
\text { in the course; current } \\
\text { computer engineering } \\
\text { student }\end{array}$ & $\begin{array}{l}\text { Four years of experience with } \\
\text { engineering design; no prior } \\
\text { awareness of design thinking }\end{array}$ \\
\hline Andy & $\begin{array}{l}\text { Research } \\
\text { assistant }\end{array}$ & Industrial design & $\begin{array}{l}\text { Design thinking expert; } \\
\text { former student in the } \\
\text { department }\end{array}$ & $\begin{array}{l}\text { Used design thinking daily as } \\
\text { an industrial design student }\end{array}$ \\
\hline
\end{tabular}




\section{Data Collection}

In this study, we collected a variety of data to explore design thinking behaviors from multiple lenses. These data include audio recordings and written notes from team meetings on instructional design of the course, design artifacts (including final course materials), interviews with team members, and semi-weekly reflections from the course instructor.

Meeting recordings and the resulting transcripts provided the primary source of data. Meetings lasted 1-2 hours and featured the team engaging in design activities surrounding the course. While not every team member participated in each meeting, at least three team members participated in all meetings. We focused on meetings during the month preceding and the month and a half after the beginning of the semester due the heavier focus on design work, rather than later meetings that tended to discuss logistics of implementation and instructor feedback on planned activities. In total, we analyzed 15 meeting transcripts totaling 17.6 hours of audio, plus detailed notes from an additional 6 meetings that were not audio-recorded. Interviews, reflections, design artifacts, and informal conversations provided context for the observed design behaviors.

\section{Data Analysis}

We used thematic analysis ${ }^{33}$ to explore how the $\mathrm{x}$-team applied design thinking to the redesign of the embedded systems course. Thematic analysis is an iterative, inductive method used to identify common and important patterns within a data set. We used a six-step process, similar to that describe by Braun and Clarke ${ }^{33}$ :

1. Reading and re-reading the meeting data

2. Generating initial codes (representing specific actions and activities related to design thinking)

3. Collating codes and identifying themes (representing connections to design thinking processes)

4. Reviewing themes in light of coded extracts and the whole data set

5. Defining and naming the themes

6. Crafting final theme narratives and connecting to the literature

In the case of this study, the focus was on patterns in the x-team's course redesign process that connected to design thinking. This was not a content analysis which sought to identify the frequency and extent to which specific design thinking processes and techniques were or were not employed. Instead, the goal was to identify how design thinking manifested within the xteam's processes. This manifestation could be perfectly aligned with design thinking as presented in scholarly and practice literature, an adaptation or extension of such methods in a new context, or alternative (and potentially conflicting) methods intended for similar purposes.

The five design thinking stages identified by Brown ${ }^{1}$ provided a foundation for this analysis (Table 2). These stages presented a basic conceptual framework within which themes related to the manifestation of design thinking were formed and categorized. We identified themes as patterns of action that connected in some way to these stages. This included patterns that 
matched the activities common to design thinkers, but it also included patterns that presented new or modified activities undertaken for similar purposes. For example, any attempts to generate ideas were considered as potential ideate themes, regardless of connection to prior design thinking literature that suggests encouraging variety, volume, and wild ideas. This allowed us to understand the team's processes that both aligned with and diverged from design thinking.

Table 2. Design thinking stages that guided analysis

\begin{tabular}{|l|l|}
\hline $\begin{array}{l}\text { Design } \\
\text { Thinking } \\
\text { Stage }\end{array}$ & Description \\
\hline Empathize & $\begin{array}{l}\text { Interacting with, observing, and getting to know users to develop cognitive, } \\
\text { affective, and experiential insights. In general, this stage involves immersive } \\
\text { and direct interaction with users (e.g., participatory research), substantive } \\
\text { efforts to develop deep empathy, and involvement of users throughout the } \\
\text { design process. }\end{array}$ \\
\hline Define & $\begin{array}{l}\text { Framing and reframing the design problem as articulated design goals and } \\
\text { criteria. Typically, the defined problem relies on insights from the empathize } \\
\text { stage and reflects a critical and unbiased understanding of the challenges and } \\
\text { needs of users. }\end{array}$ \\
\hline Ideate & $\begin{array}{l}\text { Generating concepts to address the defined problems. In general, the goal of } \\
\text { ideation is to generate a great volume and variety of concepts free from } \\
\text { restrictions of feasibility and interpersonal dynamics. }\end{array}$ \\
\hline Prototype & $\begin{array}{l}\text { Developing tangible, scaled-down, and preliminary solutions with which users } \\
\text { can interact to explore suitability, experience, and how well design criteria are } \\
\text { met. Design thinkers emphasize prototyping early and often in the process and } \\
\text { often employ quick, low fidelity methods to do so. }\end{array}$ \\
\hline Test & \begin{tabular}{l} 
Exploring the suitability of prototypes through user interaction and discussion. \\
\hline
\end{tabular} \\
\hline
\end{tabular}

\section{Results}

We found 10 themes representing ways the participants applied design thinking to the course redesign process. While not intentional, there were two themes within each of the five design thinking stages. In general, these themes demonstrated behaviors that were within the general scope of the design thinking stages, but which relaxed or diverged from key aspects of design thinking. In the sections below, we describe each of these themes and its connection to authentic design thinking practice. 


\section{Empathize}

In design thinking, the empathize stage represents an attempt to deeply understand the challenges, needs, goals, and contexts of users through immersive experiences and engagement of users throughout the process. The two themes in this section represented different patterns of engaging with two different user groups. The first theme focused on understanding students in the course through prior experience and general assumptions of learners. The second theme represented a more designerly effort to understand and engage another user, the course instructor, in the design process.

\section{Generalized assumptions about students from prior experience}

Students were one of two primary user groups originally identified by the x-team. The team's primary method for seeking information and building insights about this group came from prior experiences with electrical and computer engineering students. This came from experiences during previous iterations of the course, knowledge of students in general (from a faculty perspective), and prior experience as a student. For example, the course instructor, Michael, usually focused his insights to how students had reacted to the course in the past. He noted:

That's something that a lot of students don't really appreciate because most students now in the curriculum are from an era, or they don't know of a time when processors didn't have more than one processor on a chip. That's a natural concept for them. My chip has four cores on it, that's very natural. Before 2001 that was a very unusual thing. I try to give them some sense of that. There's probably a better way of doing that.

The team used this knowledge to build a collective understanding of students who would be taking the course. In general, since this knowledge did not come from specific users, insights applied to the entire group of students, or the potential variation in the group. Their focus was insights in two areas: student preparedness for learning and factors that could affect interest and motivation. The team sought a general understanding such that they could plan content and activities that were appropriate and engaging for the entire class.

This technique may have stemmed from deep knowledge of prior students that has grown into a composite image over time, and the assumption that future students will fit into this composite. For example, the instructor's insights came from having taught the same class several times in the past. However, since "empathic" insights here were so distanced from individual students, there was a danger that designers may miss the unique aspects that will affect students' experiences in future courses based on changing course and student populations. Further, as the below quote from Sydney indicates, such a general understanding may block the development of empathy in light of new information.

So, any of that feedback is welcome from the students. But, they also should just be a little bit patient. Because, I think-I'm sure, these days, I mean, students have a hard time being patient. They have a hard time thinking that they're going to see the benefit of this in the end, you know? 
The team recognized that the course instructor, Michael, was a key figure in their effort to revise the course. He would not only implement the course changes proposed for student users, but was an important user himself. The team, thus, involved him in regular meetings as a designer, an informant about the course setting, and a user whose needs they were trying to understand and meet, and used these meetings as an opportunity to understand and empathize with him.

One common technique was asking the instructor to describe his vision of the course, his approach to teaching, how specific aspects where developed and implemented, and assessment of prior iterations of the course. Some of this questioning led to deeper understanding of students and the course context, but it also led to insights on the instructor's teaching style, hopes for the course, and his pain points. In one instance, the team was discussing homework with the instructor, who shared his experiences with students who were caught cheating.

There have been places where people-before I got kind of depressed-people would submit their homework and it would be the same file with another person's name on the file. They would get caught and they would still try to reason why it wasn't copied. Very sad, very sad times here.

The team also continued to develop their relationship and empathy with the instructor by involving him in the design process. They frequently asked his opinion on potential ideas and acknowledged his ideas. This often led to a compromise between instructor and design perspectives, as shown below in a follow-up to the conversation above.

Sydney: $\quad$ Do you have an issue with students who, like personally if they're collaborating on the homework?

Michael: $\quad$ Also, I guess the lower the percent homework is of the grade, the more comfortable I am with them working together.

Design thinking thrives within a collaborative environment, so by sharing perspectives and building empathy for one another, the team not only learned about users and context, but built a relationship upon which further design efforts could thrive.

\section{Define}

The define stage focuses on organizing empathic insights to understand user needs and develop one or more design problems to address. The two themes in this stage demonstrated the team struggling to identify concrete problems to solve as well as identifying problems without substantive connections to empathic insights about users.

Struggling to define the "big rocks"

The term "big rocks" entered the conversation of the design team during its first meeting, via Freddie. This was an analogy for the important knowledge, skills, abilities, and attitudes around 
which the team hoped to design the course. It became evident, early in the process, that none of the individuals on the team agreed on what those big rocks should be, so the team worked to verbalize and then synthesize their individual perspectives. While many team members continued to verbalize perspectives based on their unique backgrounds and roles, there was evidence of individuals attempting to connect others' perspectives to their own to define the problems the team could work to address. For example, the following excerpt shows Sydney, a former and planned-future instructor of the course, connect her understanding of the purpose of an engineering course with the professional formation processes (building a social network and sense-making) promoted by an engineering education expert on the team.

You're teaching students the fundamentals of the field so that they go with requisite knowledge and skills to do their job. I mean that's really important to their--but there's a couple other things that are important, this networking and sense making. And I think most of us would realize that we don't do enough of that in our courses. We might expect students to get it in some other ways, but the thing is, is how can we do that, even through our courses?

This approach was further aided by abstraction laddering ${ }^{23}$, which allowed the team to consider issues at finer and coarser levels of abstraction. The team eventually formed a "consensus" of eight big rocks that guided the course as learning objectives for students. However, six of these big rocks were minor re-verbalizations of prior learning objectives of the instructor and the remaining two additions (helping the students use the tools, processes, and mindsets of design thinking; and inspiring sociotechnical thinking) were slight re-verbalizations from team members who promoted them initially. The team moved forward with a loose agreement around these problems to solve, but never quite defined them in ways that were accepted, or even understood, by all team members.

\section{Emergent and post hoc problem definition}

The other common problem definition technique was to focus on smaller scale problems that emerged throughout the design process. Some of these arose as scaled down versions of the loosely defined, overarching problems described in the above section. In other words, the team identified sub-problems related to the larger problem and moved to address those as a way to systematically address the larger problem. For example, which discussing one of the technical big rocks, the instructor, Michael, identified the following sub-problem:

The end purpose is for them to have a common definition of what embedded system means. Then we're saying, how do we actually want them to think about, once they have a definition of embedded system how do we want them to think about the bigger [picture]?

Many of the emergent problems, however, did not directly align with the larger problems the team identified. They were identified throughout meetings as offshoots of other discussions. Some of these came from the team's attempts to build empathy for the instructor. They would ask the instructor to describe an aspect of the course, which would inspire him to identify a smaller issue he had experienced in the past. In other settings, these arose from ideation. A 
specific concept would inspire the team to identify a new problem to address, or, in some cases, a previously unidentified problem that a concept they proposed would address.

In some ways, this approach represented a designerly way of thinking, in that the emergent problems sometimes stemmed from empathic insights or iterations back from the solution space (e.g., co-evolution ${ }^{34}$ ). However, these smaller-scale, emergent or post hoc problems typically represented distractions from the team's primary design work on the larger problems they had identified.

\section{Ideate}

Ideation focuses on identifying a set of potential concepts that could address the design problem. Typically, input from all team members is sought to general a large and varied pool of potential ideas. The two themes in this stage demonstrated restrictions placed on the volume and scope of ideation.

\section{Restricting the volume of ideation}

Despite frequent meetings (at least twice per week), which offered time for the broader ideation that is characteristic of design thinking, the team often emphasized an efficiency-oriented approach. Here, they would identify a problem to address (e.g., as in the define themes), identify one or two potential solutions, evaluate those solutions, and move to the next topic. For example, after the team defined their problem of connecting the final project to the course material, they identified a single idea, spent a few minutes evaluating and developing the idea, and moved to the next topic without considering alternatives:

Michael: $\quad$ So, one issue students have in general is trying to connect this to the final project. What we could do to probably help with that is we could take this chart with the "What" column, I could put some initial "whats" that are in the baseline for the project, then say, "Okay now fill in another three or four that are distinct to your problem statement." They can see how they're going to connect their "whats" to the "whats" that are part of the project already, so they can have sets for whatever.

Sydney: I like the fact that this can be connected to the project, because that would address some of the students as they're thinking.

Leo: $\quad$ Well, yeah, and that's kind of where we wanted to go, so I like that. One thing we could frame it as, "You're working in this firm. It needs to meet these criteria." The top management team says "Go."

Michael: $\quad$ "Here's your base criteria, and you have your freedom to add some other criteria." 
Leo: $\quad \quad \quad \quad$ Yeah. And that way it's starting to integrate with the work they have been doing with the project as it exists. Yeah. So, my question is, 20 minutes. Is it enough time to come up with a criterion and all the potential options?

Michael: I think if they're given some initial criteria. Because they know what direction to kind of look, and then that will get the ball, get the momentum going, starting to roll.

Sydney: $\quad$ Because then they might be more adding just a few criteria, and they would spend more time on the "hows"?

Michael: Yeah exactly.

Beth: $\quad \quad \quad Y e s$, we want the "hows" more, because they should already know the criteria, because they did all the empathize to define work, but this, that's there.

Michael: $\quad$ So, if they see some initial criteria they should then quickly-

Beth: $\quad$ The creativity will come from the "how" part.

Leo: $\quad$ Yeah. Okay.

Beth: $\quad$ Do you want to do a first pass on-

Leo: Yeah.

Beth: $\quad$--and then I can-

Leo: $\quad$ Yeah, I'll set it up.

The act of immediately evaluating ideas connects back to the assumptions about students demonstrated in the empathy stage. The team often evaluated the ideas using their assumptions about students, their knowledge and capabilities, and how they might react. An alternative way to phrase this was that the team was imagined the future use of the ideas they generated and used that as a quick way to gauge potential success. In the following example, one member of the team suggests generating a several potential ways to structure reflection questions for students to answer about their design processes. Another member immediately evaluates that idea as infeasible for students and shifts the conversation away from generating more ideas in that area.

Freddie: $\quad$ Maybe we should come up with some verbalization and see which one sounds okay for us. You know? When we're looking at pieces, once we start writing some of these, and see what we're going to share. Because all of these are valued. We need to have the empathy to read our students. We have to understand what they are, how they're looking at this course, and what they're trying to [change] in that, or help them identify as a positive. 
Sydney: $\quad$ So, I mean, I would wanna be a little bit careful that, again, just in terms of, how far along that thinking. You know, if design thinking had different levels. I don't think we can expect them to get to the highest cognitive levels of design thinking, because they are only doing it in smaller exercises, getting more awareness, basic understanding. They're not really, fully immersed in it. So, I think we wanna be a little bit careful not to expect something in the project that can't be there.

\section{Restricting the scope of ideation}

Several factors contributed to the team limiting not only the volume of ideation, but the variety. For one, as seen above, the focus on evaluation prematurely cut off idea momentum and, thus, limited any novel ideas that could have resulted from associations and synthesis of previous ideas. Secondly, the team was guided to focus on making smaller changes to the course. Some of this focus may have been based on the empathy they had developed for the instructor/codesigner. In recognizing he might be unnecessarily challenged to implement a potential solution, the designers often limited the scope of the ideas they suggested. Further, the process was constrained in an effort to secure buy-in from future instructors, and other faculty members in the department who might look upon the team's work as an example of how they might work with the team to revise their courses (i.e., "look at how simple it was for us"). The following statement from Sydney demonstrated this guideline:

We would overwhelm the [future course] instructors if we started to talk about [everything in our course]. I mean we are trying to get them to buy into this... With a focus on [future courses] and the idea is that we're bringing some of that in. That they may not be able to do the roles of redesigning their course and trying to think more deeply about their own course.

Another factor may have been the reliance on knowledge of prior solutions, e.g., in other courses. Most of the team had experienced engineering courses as both instructors and students, and were avid readers of literature on educational research and scholarly teaching. Further, the instructor had taught the course for several years. Thus, they entered ideation with an extant pool of potential solutions from past versions of the courses and other, similar courses. This was, at once, a benefit and hindrance to open-ended ideation. When problems were identified, the team was ready with easily accessible solutions from prior experience, but often also did not attempt to identify other, unfamiliar solutions.

\section{Prototype}

Prototyping emphasizes developing quick, scaled-down models of design concepts (or aspects thereof) that can be tested with users to provide formative feedback. The two themes in stage show the participants delaying prototyping, rather than acting immediately, and prototyping without physical materials that could provide a clearer picture of the proposed design. Thus, both themes represent attempts to visualize the design and gain feedback, but were enacted in ways that limited the timeliness and extent of feedback. 


\section{Confirming a plan to prototype}

Once the team had planned larger areas in which they hoped to make changes and selected specific ideas to pursue, much of the detailing of these ideas occurred outside the meetings. For example, two of the three major changes to the course (the addition of design thinking modules in lab and written reflection exercises) were delegated to smaller sub-teams. The team then used the meetings to confirm prototyping tasks and give feedback on the developed prototypes. An interesting result of this prototyping was that the prototypes and eventual implemented designs were no longer "owned" by the team as much as the individual or sub-team who created them. In the following example, a team member assigned to create the design thinking modules for lab, Leo, slipped and used "I" language before quickly correcting to "we" language.

And then next week, they'll take the personas and build a new statement and sort of revise their problem statement based on that. Then I'd like them to go through, we thought it would be good to go through an abstraction laddering assignment so they can see, "Okay,, well I'm going too narrow to high level."

This is not to say that the team was disinterested in prototyping. They sometimes just needed to be prompted to work together on a prototype, as in the example below which led to an extended period of detailing a separate design thinking module.

Leo: $\quad$ So, and potentially I could work on that this afternoon or we could work on it here if we wanted to.

Michael: $\quad$ Want to take five minutes?

Leo: $\quad$ Yeah, let's try it. I mean, that's a good testing of the activity as well.

Proceeding this positive exchange to test out an activity within the team meeting comes the development of users, a problem statement, and stakeholders by the team members. The team's familiarity with teaching this process and designing a course around it shows that they have learned something alongside the students. Overall, however, it can help them imagine the activity from the students' perspectives.

\section{Collaborative, rapid prototyping through imagination}

Prototyping also occurred during meetings without prompting. Typically, as the extended excerpt below demonstrates, this prototyping resided somewhere between ideation and true prototyping. The team collaboratively built a scenario by adding new ideas or details and imagining it's potential use with students. This resembled rapid prototyping of physical elements common within design thinking, but in an area where rough, physical models were not as obvious.

Sydney: Now, as they come up with this own story, so they're coming up with, here's an article, this is some other way that autonomous vehicles are used. Then they are, I think right? The idea is that they start right in this story, and the first step is they gotta identify who are the users or 
stakeholders? And it may not just be in that article, but they are starting to write their own story.

Michael: $\quad$ I think we planned for lab two that the pre-lab for that I think we were thinking to have that be creating a problem statement. I think that's what we're looking to-

Leo: $\quad \quad \quad \quad Y e a h$, that might be it. And it might even be before that, to start to identify the users. So, essentially, the way I was thinking about it is this article that they find is essentially analogous about finding an article in the design thinking workshop. That's a broad problem that they could potentially solve through a design process, right?

And then so this application to story is them going through one phase at a time and refining either the design problem or their design solution, kind of stepping them through this one lab at a time. And introducing it through pre-labs and post-labs and then also, Michael had the idea of having little breaks between the technical parts of the lab, and I like to think of it as design thinking sorbet, because it's kind of a palate cleanser?

Beth: $\quad$ I like that.

Leo: $\quad$ But-

Beth: Okay, here's a suggestion. I don't know how feasible this is for the class, but when the students start building their stories, they will need a lot of help in terms of who are the players in the stories. And maybe provide some really different user groups who might actually get the benefit of this robot. And that might be, maybe they are designing this system for really young kids who are between the ages of seven and nine, as part of them to understand the space. Or maybe it's for other people who would never think about that. I don't know, is that a possibility? Because if we can make them think about those different users, and the stakeholders will change.

Sydney: $\quad$ Right, yeah.

Beth: $\quad$ Because we don't want all, you know-

Michael: $\quad$ So, I think that would be a matter of when they, the final story they want to tell, just asking this, okay think about who the users are, right?

Sydney: $\quad$ And this is going to be ... so part of this depends upon the application that they end up finding, right? I mean, they're going to ... I have no idea how far and wide they're going to go with their applications. I hope they're creative with their applications. Not just because they saw the Mars rover, 
they're going at looking at those kinds of robot applications. I hope they're going into all these health care fields and things, but part of this is just entering to see where ... hopefully the problem has been given to them wide open enough, so that they do feel like they can go find all these varied applications.

\section{Test}

The test stage represents an extension of the prototyping stage, where designers receive feedback from users that can then inform iterations within the other design stages. As with prototyping, testing early and often can provide valuable feedback to improve future designs. The two themes in this stage demonstrated authentic attempts to test the design, that were limited in timeliness and direct feedback from users.

\section{Planning to secure student feedback}

The team worked throughout the semester with the understanding that the first iteration of the revised course would act as a prototype for future iterations. This, in part, came from the knowledge that the team would be working together on this course for at least four semesters, and, in part, from the ways they had approached their individual courses in the past (e.g., lessons learned transferred from one semester to the next if you taught the same course multiple times). However, in this novel design setting, the team planned several ways to secure student feedback on the course (especially the changes made) beyond their standard methods.

The planned testing methods included collecting experiential data from students through written reflections, semi-structured interviews, and weekly informal chat sessions (i.e., coffee hours). While the interviews and chat sessions did not occur due to logistical challenges, student reflections were used at strategic points during the semester to understand how students were experiencing the additions to the course. For example, the team discussed how students' interpretations differed, where those differences may have originated, and what it meant for their understanding of professional engineering within the course.

Leo: $\quad$ Looking at the question, I think there are two types. There's the students who have had internships and experiences, who have done things like design thinking, or used specific systems. So, one was more of a software engineer... And he was the one who came and talked to me after class that one time. I don't know if you remember that. But like, that's more UX [user experience] stuff... The empathy is almost not there. It's more like empathic manipulation, rather than actual empathy... But then, there's the really naïve students.

Rebecca: Yeah.

Leo: $\quad$ Where like, "Yeah, this is what engineering is going to be," and you know, they're seeing design thinking as a very general thing, and they don't understand the nuance, which we couldn't present to them. 
Rebecca: Yeah. It's kind of telling. You know, on the other hand, it could also be the more sophisticated students, who have somehow--they have, from somewhere, absorbed the idea that what you learn in college is not necessarily what you do as an engineer, but they are still misunderstanding what you actually do as an engineer. They could be like, "Oh, well you know, in class, we learned things in lock-step, and, you know, this system leads to this system," and you know. You're never going to be able to sit down, like, that's not how you do math in the real world. But they actually don't know that like, it's not even just that that's not how you do math in the real world, it's that engineers typically don't think that way. Though I guess there's also an unfortunate generalization of engineers. I don't think I actually know what engineers do, either, so ...

Stanley: $\quad$ Because they do so many different things.

Rebecca: Right! They do a lot! Like, somebody has to think about who these things are for, right? Or is that just like, somebody in marketing?

This discussion continued and eventually led the previous course instructor to propose a change to the final project based on initial tests of design thinking experiences.

Sydney: $\quad$ So, I like the idea of bringing the design thinking back more explicit into the project, where students have to prepare something as part of their final project.

\section{Feedback through informal interactions and observations}

While the team envisioned reflections as a primary medium to collect feedback from students, they tended to rely more on insights gleaned through observations during the course and informal interactions with students. For example, the team, through Michael and Sydney's communication after a jigsaw activity, learned how different classroom environments during morning and afternoon lectures affected student engagement with the same designed activity.

These are my, our reflections based on students. In the morning class, the class is a little bit more cozy. It's in the amphitheater type thing but small, so we could talk to the students easier, in a sense, and there was series of students that had me in other classes that were really excited that they're seeing me here, right? So they actually generated many questions.

Another important source of feedback was the teaching assistants, who more directly interacted with and observed students in lab. Jonathan, a teaching assistant, joined the team after his observations of students in lab provided valuable feedback. For example, he alerted the team to student experiences on a particularly difficult lab assignment, which was taking longer than expected and becoming a source of frustration to the students. Michael reacted with surprise to 
this feedback and started making plans to address the students' concerns, demonstrating the importance of alternative sources of observation.

Michael: $\quad$ I didn't prep students for that verbally before, really, as well as I could have. So, in the afternoon section I tried to add to my debriefing the reality of how the class works in general so that they didn't freak out if they were struggling for lab five.

Rebecca: $\quad$ And, so, the student was thinking "Lab five was still really hard. We weren't really ready for it. You could've used time better in class to get us more ready for it." The student, again, not really appreciating that there is a step jump in their responsibilities, and we can't prove, but our intent was that this would make them better prepared because they would've actually dug in, had the materials ready. They wouldn't have just been passive learners of it. They were active learners of it.

It should also be noted that the team also began piloting prototypes of in-lab activities with Jonathan and other teaching assistants toward the middle of the semester. Members of the x-team would present the activity to the teaching assistants, who would engage with the activity as if they were students and offered feedback based on how they thought different students would reach. These meetings were not recorded due to concerns for confidentiality, but represented an additional means in which teaching assistants acted as testing surrogates for students in the course.

\section{Discussion}

The above section reported 10 themes related to how a diverse educational x-team applied design thinking processes when redesigning an established embedded systems course for computer, electrical, and software engineering students. These themes do not necessarily comprehensively describe the team's approach, but instead focus on how the team's approach connected to the established design thinking processes of empathizing, defining, ideating, prototyping, and testing. In many cases, the team tended towards approaches that sought the basic outcomes of but did not align with the essence of design thinking that underpinned these processes. This is not to say that those approaches were ineffective (such an evaluation is beyond the scope of this study); they simply did not align well with design thinking. In this section, we explore potential reasons for differences between the team's approaches and those more aligned with design thinking. These were evident at three levels: individual lack of familiarity with design thinking, situational factors within the department, and contextual factors within course (re)design settings.

At an individual level, unfamiliarity with design thinking may have interfered with "pure" utilization of design thinking. Prior literature demonstrates many examples of novices struggling to employ design thinking methods ${ }^{35-38}$. For example, in a related study, Seidel and Fixson ${ }^{38}$ explored the use of design thinking (defined by needfinding, brainstorming, and prototyping) among novice multidisciplinary product development teams. While some "high-performing" teams were found to employ strategies related to the define, ideate, and prototype stages as 
framed in this study, other teams demonstrated novice strategies such as failing to identify a definitive need to address (which related to the emergent and post hoc problem definition theme observed among the participants in this study). Similarly, novice designers often demonstrate idea scarcity compared to idea fluency within the ideate stage ${ }^{35}$, e.g., due to idea fixation ${ }^{37}$. Both ideate themes in this study demonstrate ways that the participants limited the range of potential ideas, which supported idea scarcity. Michael, the course instructor, described the personal challenges of adopting a new design methodology in his reflections and during team meetings. In particular, he noted that initial confusion about design thinking and the habits of previous engineering and course design methods challenged his ability to engage with design thinking during the course redesign process.

Situational challenges were also evident. As part of the larger departmental initiative, the x-team was not only tasked with employing design thinking to redesign a single course; they represented an experimental prototype for future x-teams. Early in the process, the x-team emphasized lowstakes efforts and changes to secure buy-in from future instructors (who might join or form future x-teams) and ensure the sustainability of their own efforts. This approach limited opportunities for time- and resource-intensive design thinking aspects, such as regularly engaging users (i.e., students) in the design process (a key aspect of empathize) and frequent prototyping and testing, and limited the scope of ideation to smaller-scale changes. Matusovich and colleagues ${ }^{39}$ identified the importance of cost value (e.g., time) and utility value (e.g., peer and administrative support) among faculty who plan engage with transformative change in engineering education. The team's approach to limit the scope of design thinking activities aligned with these motivation priorities by effectively managing the time commitments and securing departmental support. Interestingly, this phenomenon represents a paradox between (1) authentically using design thinking to facilitate transformative change and (2) limiting the extent of design thinking (and thus potential for larger-scale change) in order to ensure any change at all.

Finally, contextual challenges in applying design thinking to course redesign were also evident. While prior literature offers some connections between design thinking and instructional design, potential challenges and misalignments have been documented ${ }^{3,27,30}$. One such misalignment is the approach toward empathy for users, and learners/students in particular. Many instructional design expert models and practices focus on learning about and from users, but focus mostly on users' prerequisite knowledge and learning capabilities ${ }^{5,29}$. This conflicts with the more holistic and empathetic focus of design thinking. In this study, the theme generalized assumptions about students from prior experience within the empathize stage demonstrated a focus on student preparedness for learning in the course. Such assumptions arose from prior knowledge of students in the course and department, and the instructional priorities of the current and former instructors. Similarly, the themes within the ideate stage demonstrated some adherence to prior curricular and pedagogical design solutions from prior courses, previous versions of the redesigned course, and evidence-based practices from the engineering education literature. This and the focus on student preparedness based on prior knowledge of students speaks to a larger issue of incumbent knowledge and priorities (related to the course environment, learners, pedagogical techniques, etc.) within education design. While such knowledge can inform the design process, it also, as seen in this study, can limit the open-mindedness that is necessary for effective design thinking, especially within the empathize, define, and ideate stages. 


\section{Conclusion}

This study explored how a team of nine engineering educators from diverse backgrounds and positions used design thinking during a recent course redesign effort. We organized findings around five common processes: empathize, define, ideate, prototype, and test. We found 10 themes representing approaches within these processes. Most of the themes described approaches that aligned with the overarching purposes of the five processes, but often differed in execution. For example, while volume and variety are typically promoted in design thinking ideation, the team limited both the volume and scope of ideation.

Collectively, these results suggest that design thinking can be a relevant methodology for supporting course (re)design efforts in engineering education, but that these efforts may be impaired by individual participant knowledge and mindsets (e.g., engineering design vs. design thinking), situational factors (e.g., securing buy-in from instructors), the complex and intangible nature of the design object (e.g., an entire engineering course), and overarching practices within engineering education and instructional design that diminish opportunities for design thinking. However, it should not be forgotten that engineering course design is a unique setting, with unique actors and a unique knowledgebase. Thus, modifications of design thinking to support more effective efforts should also be explored. In future studies, we plan to (a) further explore the individual, situational, and contextual factors that may have supported or challenged design thinking (e.g., individual mindsets), (b) investigate the effect design thinking (and lack thereof) had on design outcomes, (c) expand the study of design processes to later iterations of the course and x-teams redesign additional courses, (d) explore methods to support an effective adaptation of design thinking in engineering course design contexts, and (e) more thoroughly understand the nature of engineering course design and the role design thinking can and should play in such efforts.

\section{Acknowledgment}

This material is based upon work supported by the National Science Foundation under grant number EEC-1623125. Any opinions, findings, and conclusions or recommendations expressed in this material are those of the authors and do not necessarily reflect the views of the National Science Foundation.

\section{References}

1. Brown, T. (2008). Design thinking. Harvard Business Review, 86(6), 84-92.

2. IDEO Toolkit - Design Thinking for Educators. https://www.ideo.com/post/designthinking-for-educators.

3. Sugar, W. (2014). Studies of ID practices: A review and synthesis of research on ID current practices. SpringerBriefs in Educational Communications and Technology. DOI: 10.1007/978-3-319-03605-2.

4. Kirschner, P., Carr, C., Merriënboer, J., \& Sloep, P. (2002). How expert designers design. Performance Improvement Quarterly, 15(4), 86-104. 
5. Perez, R. S., Johnson, J. F., \& Emery, C. D. (1995). Instructional design expertise: A cognitive model of design. Instructional Science, 23(5-6), 321-349.

6. York, C. S., \& Ertmer, P. A. (2011). Towards an understanding of instructional design heuristics: An exploratory Delphi study. Educational Technology Research and Development, 59(6), 841-863.

7. Carlgren, L., Rauth, I., \& Elmquist, M. (2016). Framing design thinking: The concept in idea and enactment. Creativity and Innovation Management, 25(1), 38-57.

8. Rover, D. T., Zambreno, J., Mina, M., Jones, P. H., Jacobsen, D. W., McKilligan, S., \& Khokhar, A. (2017). Riding the wave of change in electrical and computer engineering. Paper presented at the 2017 ASEE Annual Conference and Exposition, Columbus, $\mathrm{OH}$.

9. McKilligan, S., Fila, N. D., Rover, D., \& Mina, M. (2017). Design thinking as a catalyst for changing teaching and learning practices in engineering. Paper presented at the 2017 Frontiers in Education Conference, Indianapolis, IN.

10. Simon, H. A. (1969). The sciences of the artificial. Cambridge, MA.

11. Rowe, P. (1987). Design thinking. Cambridge MA: MIT Press.

12. Cross, N., Dorst, K., \& Roozenburg, N. (Eds.). (1992). Research in Design Thinking: Proceedings of a Workshop Meeting Held at the Faculty of Industrial Design Engineering, Delft University Oof Technology, the Netherlands, May 29-31, 1991. Delft University Press.

13. Goldman, S., Carroll, M. P., Kabayadondo, Z., Britos Cavagnaro, L., Royalty, A. W., Roth, B., Hong Kwek, S., \& Kim, J. (2012). Assessing d.learning: Capturing the journey of becoming a design thinker. In H. Plattner, C. Meinel, \& L. Liefer (eds.), Design thinking research: Measuring performance in context, Springer. DOI: 10.1007/978-3642-31991-4.

14. Howard, Z., Senova, M., \& Melles, G. (2015). Exploring the role of mindset in design thinking: Implications for capability development and practice. Journal of Design, Business, \& Society, 1(2), 183-202.

15. Schweitzer, J., Groeger, L., \& Sobel, L. (2016). The design thinking mindset: An assessment of what we know and what we see in practice. Journal of Design, Business \& Society, 2(1), 71-94.

16. Dam, R. \& Siang, T. (2018). Design thinking: A quick overview. https://www.interaction-design.org/literature/article/design-thinking-a-quick-overview

17. Liedtka, J. (2018). Exploring the impact of design thinking in action. https://designatdarden.org/app/uploads/2018/01/Working-paper-Liedtka-Evaluating-theImpact-of-Design-Thinking.pdf

18. Liedtka, J., Azer, D., \& Salzman, R. (2017). Design Thinking for the Greater Good: Innovation in the Social Sector. Columbia University Press.

19. Beckman, S. L., \& Barry, M. (2007). Innovation as a learning process: Embedding design thinking. California management review, 50(1), 25-56.

20. Cooper, R., Junginger, S., \& Lockwood, T. (2009). Design thinking and design management: A research and practice perspective. Design Management Review, 20(2), 46-55.

21. Martin, R. L. (2009). The design of business: Why design thinking is the next competitive advantage. Harvard Business Press. 
22. Becker, K. H., \& Mentzer, N., \& Park, K., \& Huang, S. (2012, June), High School Student Engineering Design Thinking and Performance Paper presented at 2012 ASEE Annual Conference \& Exposition, San Antonio, Texas. https://peer.asee.org/21448

23. Conlin, L. D., \& Chin, D. B., \& Blair, K. P., \& Cutumisu, M., \& Schwartz, D. L. (2015, June), Guardian Angels of Our Better Nature: Finding Evidence of the Benefits of Design Thinking Paper presented at 2015 ASEE Annual Conference \& Exposition, Seattle, Washington. 10.18260/p.24165

24. Liu, A., \& Lu, S. Y. (2014, June), Reinforcing a “Design Thinking” Course by Restructuring Student-Instructor Interactions Paper presented at 2014 ASEE Annual Conference \& Exposition, Indianapolis, Indiana. https://peer.asee.org/22968

25. Tolbert, D., \& Cardella, M. E. (2015, June), Learning to Integrate Mathematical and Design Thinking in Engineering Paper presented at 2015 ASEE Annual Conference \& Exposition, Seattle, Washington. 10.18260/p.24416

26. Commonwealth of Australia. (2013). Creative Australia: National cultural policy. http://apo.org.au/node/33126.

27. Gibbons, A. S., \& Yanchar, S. C. (2010). An alternative view of the instructional design process: A response to Smith and Boling. Educational Technology, 50(4), 16-26.

28. Visscher-Voerman, I., \& Gustafson, K. L. (2004). Paradigms in the theory and practice of education and training design. Education Technology Research and Development, 52(2), 69-89.

29. Rowley, K. (2005). Courseware designers: A pragmatic method for the design of effective instructional systems. Journal of Educational Computing Research, 33(4), 419450.

30. Smith, K. M., \& Boling, E. (2009). What do we make of design? Design as a concept in educational technology. Educational Technology, 49(4), 3-17.

31. Roytek, M. (2010). Enhancing instructional design efficiency: Methodologies employed by instructional designers. British Journal of Educational Technology, 41(2), 170-180.

32. Luma Institute. (2012). Innovating for People: Handbook of Human-centered Design Methods. LUMA Institute.

33. Braun, V., \& Clarke, V. (2006). Using thematic analysis in psychology. Qualitative research in psychology, 3(2), 77-101.

34. Dorst, K., \& Cross, N. (2001). Creativity in the design process: co-evolution of problemsolution. Design studies, 22(5), 425-437.

35. Crismond, D. P., \& Adams, R. S. (2012). The informed design teaching and learning matrix. Journal of Engineering Education, 101(4), 738-797.

36. Dym, C. L., Agogino, A. M., Eris, O., Frey, D. D., \& Leifer, L. J. (2005). Engineering design thinking, teaching, and learning. Journal of Engineering Education, 94(1), $103-$ 120.

37. Linsey, J. S., Tseng, I., Fu, K., Cagan, J., Wood, K. L., \& Schunn, C. (2010). A study of design fixation, its mitigation and perception in engineering design faculty. Journal of Mechanical Design, 132(4), 041003.

38. Seidel, V. P. \& Fixson, S. K. (2012). Adopting design thinking in novice multidisciplinary teams: The application and limits of design methods and reflexive practices. Journal of Product Innovation Management, 30(S1), 19-33. 
39. Matusovich, H. M., Paretti, M. C., McNair, L. D., \& Hixson, C. (2014). Faculty motivation: A gateway to transforming engineering education. Journal of Engineering Education, 103(2), 302-330. 